\title{
Economic and Regional Determinants of the Location of Payday Lenders and Banking Institutions in Mississippi: Reconsidering the Role of Race and Other Factors in Firm Location*
}

\author{
W. Parker Wheatley ${ }^{+}$
}

\begin{abstract}
Using data for Mississippi, this paper revisits Burkey and Simkins' (2004) work on factors determining the number of payday lenders and banks. With data at two levels of geographic aggregation, the paper discovers whether empirical results are robust and allows for uncertainty in geographic definition of markets. Demand factors of population, income, and wealth have important impacts. Percentage of population with college education depresses numbers of payday lenders. Evidence indicates that banks are less likely to locate in African American areas, but the results show that race is neither a positive nor a statistically significant determinant of location for payday lenders.
\end{abstract}

Keywords: payday lending, banking services, discrimination, firm location

JEL Classification Codes: $G 21, L 11$

\section{INTRODUCTION}

Low-income households in the United States confront significant day-to-day difficulties in meeting needs and must often resort to borrowing. Over the last two decades, the growing demand for non-bank financial services as well as changing supply conditions of bank retail services have led to the rise of many nonbank financial institutions to meet unmet demand in U.S. retail credit markets (Stegman, 2007). The literature on the use and availability of financial services by and for the poor has grown rapidly. Aside from the early work of the Credit Research Center, Caskey $(1994,2005)$ considers the nature of financial markets for the poor in his studies of the check-cashing, payday lending, and pawnshop industries in the United States, and Elliehausen and Lawrence (2008) provide a detailed analysis of the demand conditions of payday lending. Researchers have also studied questions of the profitability of payday lenders as well as the nature of their entry, exit, and location. In that context, Flannery and Samolyk (2005) study the extent to which the interest rates charged by payday lenders are justified by the associated risk of such loans; Damar (2009) considers factors contributing to payday lender entry into local markets in Oregon; and Burkey and Simkins (2004) analyze factors affecting business location in the payday lending industry in North Carolina.

As an addition to this literature, this paper re-considers earlier work by Burkey and Simkins (2004) on the location of non-bank financial institutions such as payday lenders and the

\footnotetext{
* Earlier versions of this research were presented at the Midwest Economics Association meetings in Cleveland, $\mathrm{OH}$ as well as at departmental seminars in the Department of Applied Economics at the University of Minnesota and the Department of Economics at the College of St. Benedict|St. John's University (CSB|SJU). I am grateful to Jean Lavigne, faculty member in environmental studies at CSB $\mid \mathrm{SJU}$, for her guidance and assistance in GIS mapping and software use. I further acknowledge the financial assistance of the Faculty Development and Research Committee at CSB|SJU for its financial support of this research. Finally, I thank the editors and three anonymous reviewers for their helpful comments and suggestions on earlier versions of this paper.

+ Assistant Professor in the Department of Economics, College of Saint Benedict|Saint John's University, 37 S. College Avenue, Saint Joseph, MN 56374; E-mail: pwheatley@ csbsju.edu.
}

(c) Southern Regional Science Association 2011.

ISSN 1553-089

SRSA, 1601 University Avenue, PO Box 6025, Morgantown, West Virginia 26506-6025, USA. 
numbers of banking institutions at the zip code tabulation area (ZCTA) and county levels, with specific emphasis on the role of race as a factor in determining location. This research was also performed using census tract data; however, for reasons of space and given that the census tract results largely parallel those found using the ZCTA data, discussion of that work is omitted here but can be made available upon request.

The large number of payday lenders in Mississippi both in terms of absolute numbers and on a per capita basis drives its selection as a target for this study. Payday lending is a very common service in Mississippi in a way that scarcely has any parallels and is surprising for a highly rural state. Graves and Peterson (2008) and the Consumers Federation of America (2008) provide information to support the notion that a large portion of the generally high density can be explained by regulatory permissiveness; however, given the relatively loose regulations on payday lending, this paper then asks the question about the other factors that determine the location of payday lending stores in Mississippi relative to more formal financial institutions such as banks.

Data from the Mississippi Department of Banking and Consumer Finance was collected on the numbers and locations of all payday lenders, and data from the Federal Deposit Insurance Corporation was used to determine the number of banking institutions. These data were matched to ZCTA and county level data to study the statistical determinants of store location in Mississippi at both an aggregated county level and at the much more disaggregated ZCTA level. The results of this analysis are compared with similar research performed relative to banking and payday lenders in North Carolina (Burkey and Simkins, 2004). In particular, the paper revisits the question as to whether payday lenders primarily service markets based on race, income, and education. Moreover, it reviews the different determinants of bank locations relative to payday lenders as well as any potential geographical relationship between the two. The findings of this research counter some of the findings by Burkey and Simkins and suggest that race is not particularly important in terms of store location for payday lenders, and other standard economic factors play a much larger role.

The remainder of this paper is outlined as follows. The paper first provides a brief theoretical discussion of the factors which should give rise to larger numbers of financial institutions, whether banks or payday lenders. The paper then discusses the sources and types of data and explains the overall empirical results and findings at the ZCTA and county level regressions of the determinants of firm location for banking institutions and payday lending institutions in order to compare and discuss these results relative to those found earlier by Burkey and Simkins (2004). The paper highlights potential problems with such regression methods and provides a brief analysis which gives some additional insights on business location, particularly with regard to the extent to which race determines firm location as well as considering the role of highways. This paper provides further evidence on the factors affecting location in the "fringe" banking industry, and it differs from earlier research in highlighting the importance of traditional demand side factors as well as critically considering the possibility of important geographic factors in determining location.

\section{THEORY ON THE LOCATION OF BANKS AND PAYDAY LENDERS}

Considering the market for payday loans and banking services as either competitive or monopolistically competitive implies that the number of firms in an area should be highly related to key demand-side factors. That is, to understand how the number of stores changes, one needs

(C) Southern Regional Science Association 2011. 
to consider how demand responds to changes in its underlying determinants. In particular, considering only the demand for credit, the demand for the services of payday lenders and banks should be tied to education (as a measure of consumers' understanding of financial products), income and wealth (as measures of consumers' potential need for different sources of credit), population, the density of population, and alternative sources of credit. This list of factors is not exhaustive but clearly provides key factors in store location decisions.

The following discussion therefore highlights some predictions relative to changes in these preliminary demand side factors. While the discussion focuses more heavily on payday lenders, reference will be made to banking services as appropriate. First, as education increases, consumer understanding of financial products increases; therefore, one would expect that higher levels of education would lead consumers to better understand the high cost of payday loans and therefore reduce their willingness to use the products. Consequently, fewer payday lenders would be located in communities with higher general levels of education. Income and wealth should similarly reduce consumer usage of payday loans because consumers would have less need of them. Consequently, there should be fewer stores in locations with relatively high levels of income and wealth. This relationship, however, could be nonlinear for very low levels of income given that payday lenders require that their borrowers be "banked," and the poorest individuals tend not to have bank accounts. In the case of banks, since banks provide a broad array of nonloan services to consumers, one would expect higher levels of income to nonetheless increase the demand for their services. One would therefore expect to find more banks in areas with higher levels of income and wealth. On a related matter, households with a younger head of household and households that rent tend to have fewer assets and less access to credit; therefore, their demand for payday lenders should be higher. However, the relationship between such values and the number of banks would seem to be ambiguous except to the extent to which such variables are also correlated with wealth.

Factors that directly increase the number of users of financial services should increase the numbers of both payday lenders and banks in a given location. Consequently, there should be a direct relationship between total population and the number of buyers at both banks and payday lenders. As such, higher populations in ZCTAs, census tracts, and counties should translate into more banks and payday loan stores. However, an overall high level of population in an area does not necessarily translate into high levels of foot traffic for both banks and payday loan stores. Consequently, greater density of the population (as measured by an urban designation) captures a further dimension of how population will lead to more foot traffic for any given business and would therefore lead to more profitability.

Finally, race does not seem to enter directly into any basic economic explanation of the location of stores. However, the one factor which could increase the number of payday lenders that does derive from race is an indirect relationship. Specifically, if the history of "redlining" and discrimination against African Americans in Mississippi led to less availability and convenience of banks, then African Americans would have less access to traditional banking services and might therefore have a greater demand for payday lending services, hence increasing the demand for such businesses in counties and ZCTA's with greater proportions of African Americans. However, given the indirect and tenuous nature of this relationship, we do not expect to find a large effect, if any, of racial composition on the number of payday lending stores in majority African American areas. Other minority communities might also be affected 
by either targeting or discrimination; however, it would seem that any such effects would largely be subsumed by other important economic variables such as income and wealth.

The above provides a general discussion of some theoretical determinants of the number of payday lenders and banks in a given area; however, as appropriate, a few other items relative to Mississippi will be added in the subsequent discussion of the empirical specification.

\section{DATA SOURCES AND COLLECTION}

Data on the location of payday lenders were provided for a fee by the Mississippi Department of Banking and Consumer Finance and include all payday lenders licensed in Mississippi at the beginning of 2008. Data on banks and related financial institutions were found from the FDIC database which provides statistics and details on depository institutions (http://www2.fdic.gov/sdi/index.asp). This data includes all banks in business as of January 2009 and is parallel with that of the data on payday lending businesses. Notably, bank or other financial institution (e.g., mutual savings banks) locations that did not provide lending services were removed from the list of locations. Since these locations tend to be either ATM's or administrative offices, their exclusion is appropriate to avoid over counting the number of lending institutions in a region. Each address for banks and payday lenders was matched to each ZCTA and county using ArcMap in order to obtain counts of these institutions. One payday lender out of 1,039 and nine banks out of 881 depository institutions had to be removed due to problems verifying exact geographic location information. In addition to the numbers of payday lenders and banking institutions in Mississippi, the location and number of casinos in Mississippi was obtained from the Mississippi Gaming Commission (http://www.mgc.state.ms.us/). As with the banking and payday lending data, each address was matched to each geographic level to obtain counts for each level and area. These data are included in the payday lender regressions in recognition of the possibility that casinos can stimulate a demand for payday loans.

Economic and demographic data were obtained from the Bureau of Census SF3 files for the 2000 Census. These data were collected for both the ZCTA and the county level. Particular data derived from or used without manipulation include the Gini coefficient, median household income, median home value, percent of population in urban areas, percent of population that is African American, percent of population that is Native American, percent of households in poverty, percent of housing that is renter occupied, and the percent of households having at least some college education. For the purposes of comparison with earlier research, these variables closely parallel the data in the Burkey and Simkins (2004) paper, and as with that paper, when considering the case of ZCTAs, 35 observations are omitted due to having fewer than 100 residents, and three are omitted because of limited data on one or more of the variables. These latter three omissions correlate with three Mississippi colleges: Millsaps College in Jackson, Mississippi; Mississippi State University in Starkville; and the University of Mississippi in Oxford. One substitution of variables occurs relative to the Burkey and Simkins work, i.e., to include the poverty rate as opposed to the percent of the population on public assistance. The poverty rate is highly related to the percent of the population using public assistance and picks up variation not otherwise measured by the above mentioned income variable and Gini coefficient. Also, this research includes a proxy for local wealth (log of median home value) in the form that was not included in the Burkey and Simkins paper, and it is expected that this variable will pick up a source of demand for payday lending and banking services not captured by the other income-related variables. On the whole, these data are consistent with the many studies that have 
attempted to analyze the factors that affect demand for payday lending services as shown most recently in the work of Elliehausen and Lawrence (2008).

Finally, two control dummy variables are used to account for counties and ZCTAs affected by hurricane Katrina and counties in the region known as the Mississippi Delta. The counties (Hancock, Harrison, and Jackson) on the Gulf Coast of Mississippi were significantly affected by hurricane Katrina, and one would expect that while the decline in the local economy might stimulate demand for banking and payday lending services, the overall infrastructure in the area would simply be unable to house as many of such businesses after that event as compared with before it. The Mississippi Delta is included because it represents a geographically and economically distinct region of Mississippi, characterized by extreme poverty and low population levels as well as historical neglect by the state government even relative to the rest of Mississippi. Its historical and cultural distinctness is captured in Willis (2000), Cobb (1994), and Cohn (1935). Its geographic scope is somewhat uncertain; although there is large overlap among various sources (e.g. http://www.deltacouncil.org/), and the set of counties and related ZCTAs included as being within the Delta were chosen after a consideration of historical sources, how various current organizations such as the Delta Council identify counties, and the demographic and economic data of counties in Mississippi. Four counties often considered Delta counties (Tate, Panola, Desoto, and Warren) were excluded because of significant differences in demographics and the fact that they are at the extreme ends or borders of the traditional Delta region. Table 1 below provides the summary statistics for all data at both levels of geographic aggregation.

As noted, earlier research by Burkey and Simkins (2004) studied the factors affecting location of stores in North Carolina. This effort attempts to replicate that work for Mississippi. While the Burkey and Simkins (2004) paper focuses on data at the Zip Code Tabulation Area (ZCTA) level only, this paper provides similar analysis at the county level as well. Given the nature of markets and high dependence on automobiles for business, highways likely play an important role in the location of stores and perhaps argue against breaking down the counties into finer economic and demographic regions. In one sense, finer divisions of the regions could increase the probability that store location is unrelated to its actual ZCTA but is related to adjacent ZCTAs. Considering determinants of location at the county level recognizes the possibility that the market for payday lending is not as geographically small as ZCTAs, particularly in urban settings. These county-level divisions should be less subject to such spatial correlations given the greater distance required, at least in Mississippi, to travel from one county's population center to another county's population center and hence the very low convenience of traveling to payday lenders in other counties. However, while such aggregation reduces potential problems of spatial correlations, we lose some of the richness and variation available at the ZCTA level. By considering the determinants of payday lender and banker locations at the ZCTA and county level, this research balances these problems and allows for observations of the extent of the robustness of results and comparison of results across different levels of geographic aggregation.

. For the sake of consistency with the earlier research by Burkey and Simkins (2004), the bank regressions include the number of payday lenders as a regressor and vice versa. This inclusion ostensibly allows one to consider the possible geographic complementary or substitutability of banks for payday lenders. However, the complementarities found in this paper would seem to be an artifact of factors unrelated to the services provided by these businesses and 
TABLE 1: Summary Statistics of Data at the ZCTA and County Levels

\begin{tabular}{lrrr|rrrrr}
\hline & \multicolumn{3}{c|}{ ZCTA } & \multicolumn{5}{c}{ Counties } \\
Variable & Mean & \multicolumn{1}{c|}{ Dev. } & \multicolumn{1}{c}{ Min } & Max & Mean & Dev. & Min & Max \\
\hline Store Numbers & & & & & & & & \\
Payday lenders & 2.54 & 5.09 & 0 & 31 & 12.67 & 12.95 & 0 & 78 \\
Banks & 2.13 & 3.47 & 0 & 20 & 10.62 & 11.43 & 1 & 58 \\
Economic Variables & & & & & & & & \\
Median household income & $\$ 28,478$ & $\$ 8,169$ & $\$ 11,042$ & $\$ 73,938$ & $\$ 27,958$ & $\$ 5,758$ & $\$ 17,235$ & $\$ 48,206$ \\
\%\% renter occupied housing & 23.59 & 14.07 & 0.00 & 100.00 & 24.39 & 8.67 & 13.03 & 48.19 \\
\% of population in poverty & 22.59 & 10.72 & 0.00 & 59.52 & 22.86 & 7.33 & 7.11 & 41.13 \\
Gini & 0.44 & 0.07 & 0.04 & 0.71 & 0.48 & 0.04 & 0.38 & 0.59 \\
Median home value & $\$ 59,895$ & $\$ 20,927$ & $\$ 0$ & $\$ 192,600$ & $\$ 61,739$ & $\$ 15,189$ & $\$ 37,100$ & $\$ 117,000$ \\
Casinos & 0.07 & 0.54 & 0 & 7 & 0.39 & 1.55 & 0 & 9 \\
$\begin{array}{l}\text { Population and Demographic Data } \\
\text { Total population }\end{array}$ & 6,948 & 8,520 & 105 & 42,040 & 34,691 & 38,538 & 2,274 & 250,800 \\
\% Urban & 21.16 & 33.24 & 0.00 & 100.00 & 30.79 & 25.10 & 0.00 & 84.81 \\
\% African American & 40.63 & 26.74 & 0.00 & 100.00 & 39.69 & 20.20 & 3.14 & 86.13 \\
\% Native American & 0.33 & 1.74 & 0.00 & 29.78 & 0.43 & 1.38 & 0.00 & 11.93 \\
\% young headed & 22.71 & 7.18 & 0.00 & 100.00 & 22.66 & 2.51 & 16.84 & 29.45 \\
\% with college & 35.67 & 11.42 & 4.68 & 87.35 & 37.24 & 8.54 & 25.05 & 64.71 \\
\hline \hline
\end{tabular}

more causally connected to other economic, demographic, and logistical factors, as well as likely zoning limitations placed on commercial activity

\section{ECONOMETRIC METHODS AND RESULTS}

The basic approach of this statistical analysis is to determine the extent to which key economic and demographic variables affect the number of stores in each of the ZCTAs and counties in Mississippi. Importantly, the dependent variable in such research is count data, and thus is more appropriately considered using discrete dependent variable models. The Poisson regression model is the standard model for such study; however, given the potential high degree of dispersion of the dependent variable data, it is important that we ask whether the data satisfy the requirement of equality between the mean and variance of the dependent variable. While this sort of problem is more highly probable with the disaggregated data, we consider its possibility at each level of geographic aggregation. We first run the regressions using a negative binomial technique, which then allows us to test whether the mean and variance of the dependent variable (either bank or payday lender counts) are equal.

Unlike Burkey and Simkins (2004), we then go further by recognizing that excess zeros in the dependent variable also signal the possibility of something akin to selection bias in that a county or ZCTA first must reach some threshold level in underlying economic and demographic data in order to give rise to any observations of banks or payday lenders. Once a ZCTA or

(C) Southern Regional Science Association 2011. 
county surpasses some threshold in its economic and demographic data, the number of counts follows a Poisson or negative binomial process. This particular problem has received increased attention in various strands of the literature and has been addressed by Lambert (1992) and Greene (1994) in theoretical settings and used by numerous authors in an applied setting (e.g., Bekkerman, Goodwin, and Piggot (2008) and Daunfeldt, Rudholm, and Bergstrom (2006)). The approach to this problem that is used here is as follows:

(1) Test for overdispersion, i.e., that the mean is not equal to the variance, without attempting to account for excess zeros.

(2) If there is overdispersion then, as suggested in Greene (2000) and as performed by Burkey and Simkins (2004), the negative binomial regression method is preferred to using a Poisson regression.

(3) In either case, to account for selection bias giving rise to excess zeros and distinguish such problems from other causes of overdispersion, we follow Greene (1994) in using the zeroinflated Poisson regression (in cases where overdispersion does not appear present from the results of the negative binomial regression but where significant numbers of zeros appear in the dependent variable) and use the zero-inflated negative binomial regression (in cases where evidence suggests the presence of overdispersion). Using Vuong's nonnested test for competing models, both methods allow for testing the preferability of the zero-inflated models relative to the simple Poisson and negative binomial regressions. When using the zero-inflated negative binomial regression, one is also able to test its appropriateness relative to the zero-inflated Poisson regression using a standard likelihood ratio of test of the equality of the mean and variance of the distribution after accounting for excess zeros arising from threshold effects.

The basic regression model includes the following independent variables: percent of population in urban areas, the log of population, the log of median household income, the percent of the population in poverty, the Gini coefficient of the area, the percent of the population older than 25 with some post-secondary education, the percent of households with younger heads (1535 ), the log of median home value, the percent of occupied housing that is renter occupied, the percent of the population that is African American, and the percent of the population that is Native American. Finally, given the significant disturbances on the Gulf Coast of Mississippi that occurred between the collection of census data (2000) and the data on the number of payday lenders per county, we also include dummy variables for the three counties on the Gulf Coast (Harrison, Hancock, and Jackson counties). As discussed, we include a dummy variable to account for counties in what is known as the Mississippi Delta to control for suspected unobserved differences of that region from other regions in the state. Finally, for the payday lender regressions only, we include a variable on the number of casinos per county or ZCTA. The inclusion of this variable is discussed earlier; however, it is also intended to prevent overstating the statistical influence of a large Native American population on the numbers of payday lenders given that one county with a relatively large percentage of Native Americans (Neshoba county, in particular) also contains several Native American-owned gambling facilities. For purposes of direct comparison with the Burkey and Simkins paper, the results and approach for the ZCTA level regressions will be presented and interpreted first, and the paper then presents and discusses results from the county level regressions. 
TABLE 2: Factors Affecting Bank and Payday Lender Locations at the ZCTA Level

\begin{tabular}{|c|c|c|c|c|}
\hline \multirow[b]{2}{*}{ Variable } & \multicolumn{2}{|c|}{ Bank Regression } & \multicolumn{2}{|c|}{ Payday Lender Regression } \\
\hline & Coefficient & $p$-value & Coefficient & $p$-value \\
\hline & \multicolumn{2}{|c|}{ Poisson Regression } & \multicolumn{2}{|c|}{ Zero-inflated Negative Binomial } \\
\hline Number of Bankers & & & 0.04 & 0.01 \\
\hline Number of Payday Lenders & 0.03 & 0.00 & & \\
\hline Percent Urban & 0.47 & 0.03 & 0.97 & 0.00 \\
\hline Log of Population & 0.83 & 0.00 & 1.21 & 0.00 \\
\hline Log of Median HH Income & -0.11 & 0.82 & -1.53 & 0.07 \\
\hline Percent of Population in Poverty & 0.77 & 0.54 & -6.07 & 0.01 \\
\hline Gini & 1.82 & 0.07 & 3.65 & 0.01 \\
\hline Percent with Some College & 0.61 & 0.27 & -3.07 & 0.00 \\
\hline$\%$ of Younger Headed Households & -1.15 & 0.23 & -0.20 & 0.89 \\
\hline Log of Median Home Value & 0.17 & 0.54 & 0.25 & 0.58 \\
\hline Percent Renter Occupied & -0.10 & 0.87 & 1.12 & 0.23 \\
\hline Percent African American & -1.29 & 0.00 & -0.07 & 0.88 \\
\hline Percent Native American & 0.23 & 0.91 & 3.93 & 0.17 \\
\hline Katrina County & -0.44 & 0.00 & -0.79 & 0.00 \\
\hline Delta County & 0.09 & 0.55 & -0.08 & 0.65 \\
\hline Casinos & & & -0.17 & 0.03 \\
\hline Constant & -8.20 & 0.07 & 3.18 & 0.67 \\
\hline $\operatorname{LR} \chi^{2}(14$ dof $)$ & \multicolumn{2}{|l|}{1320.47} & $\operatorname{LR} \chi^{2}(15$ dof $)$ & 257.02 \\
\hline \multirow{5}{*}{ Prob $>\chi^{2}$} & \multirow{5}{*}{\multicolumn{2}{|c|}{0}} & Prob $>\chi^{2}$ & 0.00 \\
\hline & & & Nonzero obs & 165 \\
\hline & & & Zero obs & 242 \\
\hline & & & Vuong test stat & 2.38 \\
\hline & & & Prob $>z$ & 0.0088 \\
\hline
\end{tabular}

\subsection{Zip-Code Area Results}

Testing for appropriate regression models yielded different outcomes for the bank level regression and payday lender regression, perhaps reflecting the more even dispersion of banks relative to payday lenders. Tests for overdispersion in the bank regression indicate a failure to reject the null hypothesis of equal mean and variance of the dependent variable; therefore, a Poisson regression is used in that case. In the payday lender regression, tests indicate that the appropriate regression model is the zero-inflated negative binomial regression. For both regressions, the likelihood ratio test for the overall significance of the regression permits the rejection of the null hypothesis of all coefficients simultaneously having no effect. Table 2 below provides the regression statistics and coefficient estimates for both the bank and payday lender regressions.

First, considering the banking regression, a number of the coefficients are statistically significant, and most coefficients for which reasonable predictions can be made have the (C) Southern Regional Science Association 2011. 
appropriate sign. As expected for such demand side factors, the percent of the population that is urban and the $\log$ of the population are both positive and significant. Similarly, the Katrina variable is negative and statistically significant. The other geographic variable, the Delta dummy variable, has a positive but not statistically significant effect. Other variables' coefficients that have the predicted sign but are not statistically significant include the percent of younger-headed households, the log of median home value, the percent of renter occupied housing, and the percent of the population with some college. The percent of younger headed households and of renter occupied housing would tend to be related to lower wealth in a particular ZCTA and therefore lower overall demand for general banking services; therefore, finding a negative sign on their coefficients is consistent with expectations. Similarly, obtaining a positive coefficient on the log of median home value would be appropriate given that wealthier households would tend to own higher valued homes and would have a higher demand for banking services. Finally, given our earlier argument with regard to the relationship between education and demand for banking services, the positive sign on its coefficient provides modest validation.

Other income variables which capture the central tendency and dispersion of income (log of median household income and percent of population in poverty) have signs different from what one might predict. In particular, a negative although not statistically significant sign is found on the median household income variable, while a positive coefficient is found on the poverty variable. The other income dispersion variable that one might expect to have some perhaps ambiguous effect is the Gini coefficient; it appears to have a positive and modestly statistically significant effect on the number of banks in a ZCTA. Finally, the race variables provide at least one interesting result. While the coefficient on the Native American variable is not significant, the coefficient on the African American variable is negative and statistically significant, thus indicating, at least for this data, that the percent of the population that is African American has a strong negative effect on the number of banks in a ZCTA. While distressing, this result is unsurprising given the history of banking discrimination in America and the pull back of banks from many poor and minority communities in the 1980s. (Caskey, 1994, pp. 90-97) As with other studies (Figlio and Genshlea, 1999), this result and the negative effect would seem to indicate that banking services are less available at the margin to African Americans and points to creating incentives and policies to broaden access of banking services in these communities. However, one must recognize that this effect could also arise from the fact that African Americans tend to have less demand for such services due to their generally lower incomes and wealth. That is, one must view such results carefully given the high negative correlation between race and variables such as wealth, income, and education.

In the payday lender regression, several more coefficients exhibit statistical significance. As with the banking regression, the coefficients on the percent of the population that is urban and the log of the population are both positive and statistically significant as expected. The $\log$ of median household income variable has a negative and statistically significant coefficient under a one-tailed assumption (i.e., by dividing the $p$-value by 2). The percent of the population in poverty has a negative and statistically significant effect on the number of payday lenders in an area. This result may seem counterintuitive; however, one might explain it as capturing the nonlinearity in the effect of income on the number of payday lenders. In particular, while declining incomes will tend to increase the number of payday lenders, if incomes fall too low as manifested by high poverty rates, then the number of households that can use a payday loan declines (i.e., they have no regular job, no regular source of income, and do not make use of banks). The income dispersion measure as captured by the Gini coefficient has a positive and 
statistically significant coefficient. One might reasonably argue the appropriateness of this result as it captures something of the character of the number of people in the lower quantiles of income, and as it grows, ceteris paribus, the numbers of potential borrowers increase.

Factors that relate to wealth and/or life experience, including percent of population with some college, percent of younger headed households, log of median home value, and percent of housing that is renter occupied, yield a mixed picture in terms of results, perhaps due to excessive correlation across factors. In any case, the percent of the population that has some college education has a negative and statistically significant sign on its coefficient as is expected and argued. This result supports earlier arguments on the effect of education on consumer understanding of the real costs associated with payday loans. Alternatively, one might also argue that individuals with more education have a lower discount rate on the future and therefore are less likely to be willing to take on such high interest loans in any case. Whether education is itself a causative factor cannot be ascertained; however, such possibilities merit further consideration. The other coefficient from among this group is that on the percent of housing that is renter occupied, and it is positive as expected but not statistically significant. Notwithstanding its statistical insignificance, the result provides evidence that greater numbers of households with lower wealth (as measured by a household's inability to own a home) will tend to be more conducive for the establishment of payday lenders. The two anomalous results are discussed as follows. The coefficient on the percent of younger headed households is negative and, while not statistically significant, raises questions about the earlier arguments related to this variable. Finally, the coefficient on the log of median home value is positive, contrary to expectations.

Of some importance is the finding that the percent of the population that is African American has a negative and statistically insignificant coefficient such that we fail to reject the null hypothesis of no effect. This result is in direct contradiction to the findings in Burkey and Simkins (2004) and would seem to call into question claims of racial targeting of African American communities on behalf of payday lenders. On the other race variable, we find a strong positive but not statistically significant relationship between the percent of the population that is Native American and the number of payday lenders.

The geographic controls, the Katrina and Delta dummy variables, both appear to have a depressing effect on the number of payday lenders in a ZCTA; however, only the Katrina dummy variable has a statistically significant coefficient. Of mild interest is that the negative effect of Katrina appears stronger in the payday lender regression than in the bank regression, indicating perhaps the more challenging proposition of locating retail store or "strip mall" space, a common site of payday lenders as compared with banks, in the post-Katrina Gulf Coast economy. Simply put, counties which were most severely hit by Katrina will have fewer payday lenders by virtue of the lost commercial space in the area. Finally, the coefficient on the casino count variable is negative and statistically significant, contrary to expectations.

\subsection{County-level Results}

In testing for the appropriate regression model, results indicate a failure to reject the hypothesis that the mean and variance of the dependent variables are equal, and given relatively few zeros in the dependent variables at the county level for both the banking and payday lender regressions, the Poisson regression model for the county level regressions is used. Table 3 below provides the results of these regressions. For the bank regression, while the overall explanatory power of the regression is quite good, the log of population and the Katrina dummy variable are 
TABLE 3: Results of Poisson Regressions: Factors Affecting Payday Lender Store and Banking Locations at the County Level

\begin{tabular}{|c|c|c|c|c|}
\hline \multirow[b]{2}{*}{ Variable } & \multicolumn{2}{|c|}{ Bank } & \multicolumn{2}{|c|}{ Payday Lender } \\
\hline & Coefficient & $p$-value & Coefficient & $p$-value \\
\hline Count of bankers & & & -0.01 & 0.37 \\
\hline Count of payday lenders & 0.00 & 0.536 & & \\
\hline$\%$ urban & -0.31 & 0.503 & 1.16 & 0.01 \\
\hline Ln (population) & 1.10 & 0 & 1.00 & 0.00 \\
\hline Ln (median hh income) & 0.93 & 0.279 & -0.27 & 0.72 \\
\hline$\%$ of population in poverty & 2.94 & 0.25 & 1.03 & 0.64 \\
\hline Gini & 1.49 & 0.566 & -4.05 & 0.08 \\
\hline$\%$ with some college & 0.10 & 0.917 & -2.01 & 0.04 \\
\hline$\%$ of households with young heads & -1.52 & 0.53 & -1.22 & 0.60 \\
\hline Ln (median home value) & 0.55 & 0.259 & 0.14 & 0.74 \\
\hline$\%$ renter occupied & -0.30 & 0.822 & 1.65 & 0.23 \\
\hline$\%$ African American & -0.76 & 0.179 & -0.32 & 0.52 \\
\hline$\%$ Native American & -0.01 & 0.997 & 5.25 & 0.03 \\
\hline Katrina County & -0.47 & 0.007 & -0.92 & 0.00 \\
\hline Delta County & 0.25 & 0.211 & -0.42 & 0.02 \\
\hline Casinos & & & -0.01 & 0.75 \\
\hline Constant & -25.25 & 0.002 & -4.44 & 0.56 \\
\hline \multicolumn{2}{|l|}{ Bank Regression Statistics } & \multicolumn{3}{|c|}{ Payday Lender Regression Statist } \\
\hline Wald $\chi^{2}(14$ dof $)$ & 687.87 & & Vald $\chi 2(15$ dof $)$ & 781.36 \\
\hline Prob $>\chi^{2}$ & 0.00 & & rob $>\chi^{2}$ & 0.00 \\
\hline Pseudo $R^{2}$ & 0.6594 & & seudo $R^{2}$ & 0.6599 \\
\hline
\end{tabular}

the only two explanatory variables for which we can reject the null hypothesis of no effect. For these two cases, the signs of the coefficients are appropriate in that the log of population has a positive effect on the number of banks, and the sign of the Katrina dummy variable is negative and significant in accord with the notion that some banks might have ceased operations in the aftermath of hurricane Katrina. No other variables appear to be significantly different from zero given the two-tailed $p$-values provided or even in the cases where a sign is theoretically predicted and a one-tailed $p$-value could be used.

The signs of several of the regression coefficients are consistent with theoretical predictions. In particular, economic values that would seem to predict or cause a larger number of banks in a particular county, such as the log of median household income, the percent of the population with college education, and the log of median home values, are all positively related to the number of banks; while the coefficients on the percent of younger head households and the percent of housing that is renter occupied are negative as would be consistent with earlier comments. In particular, the proportion of the population with some college education is positively related to the number of banks in a county. From a consumer's perspective, more 
educated and wealthier individuals tend to have a greater desire for banking services, while those with fewer assets would have lower need (Hogarth, Anguelov, and Lee, 2003). Anomalous positive signs are observed on the percent of the population that is urban and the percent of population in poverty. Unobserved conditions in the Delta counties tend to place a modest, although not statistically significant, upward pressure on the number of banks in this region controlling for all other variables. The coefficient on the Native American variable is quite small, and it is not statistically significant; however, the coefficient on the African American variable is negative and, while not statistically significant, would indicate a strong downward influence of a relatively large African American population on the number of banks in a county.

When reviewing the payday lender regression, the overall explanatory power of the regression remains quite good, and the number of variables that has statistically significant influences on the number of payday lenders in a county is greater than that for the banking regression. In particular, the log of the population and the percent of the population characterized as urban both have strong and statistically significant effects on the number of stores in a county. Of some interest is the fact that the percent of the population with some college is negatively related to the number of stores in a county, again validating earlier arguments and statistical evidence about the potential role of education. As in the case of the bank regression and the ZCTA regressions, the coefficient on the Katrina dummy variable is strongly negative and statistically significant. The Delta dummy variable has a negative and statistically significant coefficient, indicating perhaps that even after controlling for population, income, wealth, education, etc., the profitability of payday lenders in that region is substantially lower.

Cases where the coefficients are not statistically significant but of the predicted sign are as follows: log of median household income, percent of population in poverty, and percent of homes that are renter occupied. In particular, we note that the coefficient on the log of median household income is negative, in line with the idea that lower-income households will have greater demand for payday lenders. This finding is also consistent with the positive signs found on the percent of population in poverty and the percent of housing that is renter occupied variables. Contrary to intuition and although not statistically significant, we find that the sign on the younger household variable is negative, while the coefficient on median home value is positive. Directly counter to the results found in Burkey and Simkins is the fact the coefficient on the Gini Coefficient is negative, albeit only with mild statistical significance; however, this finding differs from the results in this paper at the ZCTA level of geographic aggregation. The coefficients on the race variables are negative but not statistically significant for the African American variable and positive and statistically significant for the Native American variable. This latter result perhaps follows from a couple of confounding factors. First, there is one county in Mississippi with a particularly sizeable Native American population, Neshoba County. Second, this county not only has a large Native American population but is also home to large casinos; however, since the payday lender regression controls for the number of casinos that would tend to attract a large number of payday lender clients, we would not expect to see such a strong effect. A concluding note is that the coefficient on the number of bankers in a county appears to have an insignificant effect on the number of payday lenders in a county.

(C) Southern Regional Science Association 2011. 
Before concluding this section, the paper addresses the issue of location from a spatial perspective that is not easily dealt with within a regression framework. While the placement of major highways and roads is beyond the scope of this study, highways represent the main commercial conduits of much of the state of Mississippi, and since businesses of all types wish to be located "closest" to the greatest density of consumers and the greatest amount of road traffic for reasons of ease of access to consumers, the location of roads is likely predictive of where stores reside. As it turns out, over 90 percent of all payday lenders in Mississippi are located within a mile of a primary highway in the state of Mississippi, almost 80 percent are located within $1 / 2$ a mile of a primary highway in the state, and over 60 percent are located on major state highways and roads.

FIGURE 1. Race, Roads, Payday Lender Location in Towns of the Mississippi Delta

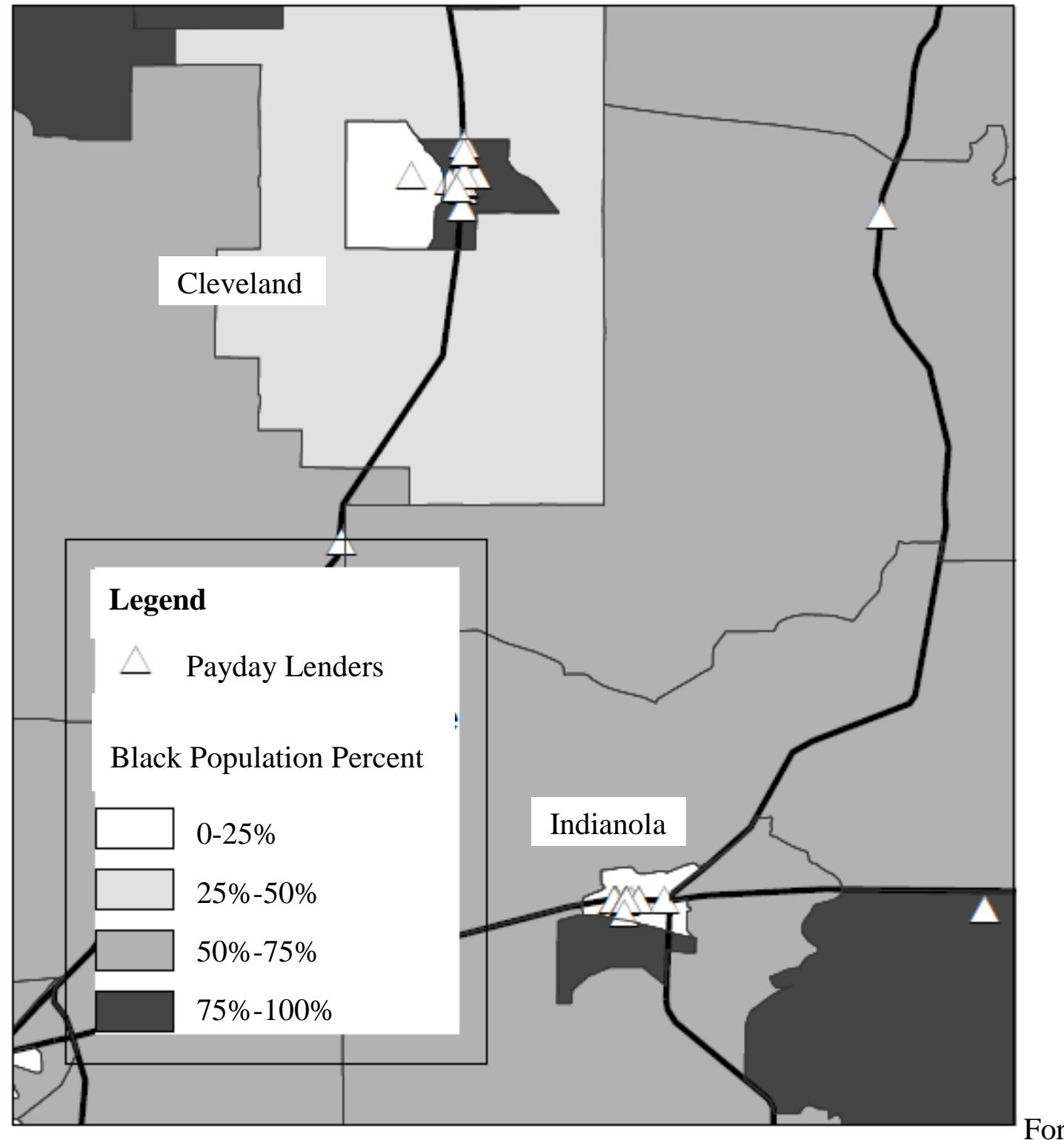


For consideration, graphical presentations are included that call into question the notion of racial targeting and support a more transportation and traditional economic basis for store location. Figure 1 and Figure 2 show the locations of payday lenders and the African American percentage of the population of different areas by shading (darker shading implying higher African American percentages). In Figure 1, two smaller towns in Mississippi-Cleveland and Indianola - are shown. The payday lender locations, denoted as white triangles in this case, are almost completely in a majority African American area in Cleveland and in a majority white area in Indianola. The main commonality between these two clusters of stores is that the major commercial roads of the region pass through the geographic division where payday lenders are located-Highway 61 in the case of Cleveland and Highway 82 in the case of Indianola. Figure 2, a map of Jackson, the state capitol, further demonstrates the importance of roads for payday lenders. In particular, one observes clustering of stores along major roads but a mild impression of slightly more payday lenders in the predominantly African American areas. It is also obvious that the number of payday lenders is quite large in other areas and located along major commercial roads. Observations of store locations across the state matched with the racial composition of census tracts and road location provides mild evidence that clusters of stores in a given geographic area are driven not by race but by major commercial routes in the state.

\section{CONCLUDING COMMENTS}

In a national climate of concern about credit markets and in the historical context of a dramatic growth in fringe financial institutions in the United States, this paper provides further analysis of the determinants of the location of payday lenders that both validates previous findings in the area and seems to challenge other findings. While the results from the banking regressions tend to be relatively weak, the general thrust of the payday lender regression results support the idea that factors affecting the location of stores are highly demand driven. More specifically, what is found is that three variables - the percent of population that is urban, the $\log$ of the population, and the percent of the population with some higher education - are robust to all levels of geographic specification both in terms of sign and level of statistical significance. Importantly, these three key variables are also found to be significant in the Burkey and Simkins (2004) paper. The first two variables are unsurprising and relate to traditional demand side predictions, and the education variable perhaps merits more consideration as to whether it is because it correlates with wealth or other reasons.

Similarly, the log of median household income and the percent of housing that is renter occupied both have signs that are robust to levels of aggregation, although neither is regularly statistically significant. Of some note is that the Burkey and Simkins paper shows that median household income is negatively related to the number of payday lenders, a result which is also found here. However, while this work agrees with the claim that payday lenders tend to locate in more urban areas with less-educated citizens, little evidence is found to support the hypothesis that African American communities are targeted by payday lenders. We further consider the problem and limits of any relationship between the percent of the population that is African American and the location of payday lenders through the display and inspection of two maps in this paper that seem to show that major road location is more predictive of payday lender location than minority composition of a given area. That being said, the research indicates that African-American communities at all geographic levels have less access to banks in that fewer banks reside in geographic areas with high African-American populations.

(C) Southern Regional Science Association 2011. 
FIGURE 2. Race, Roads, and Payday Lender Locations in Jackson, MS

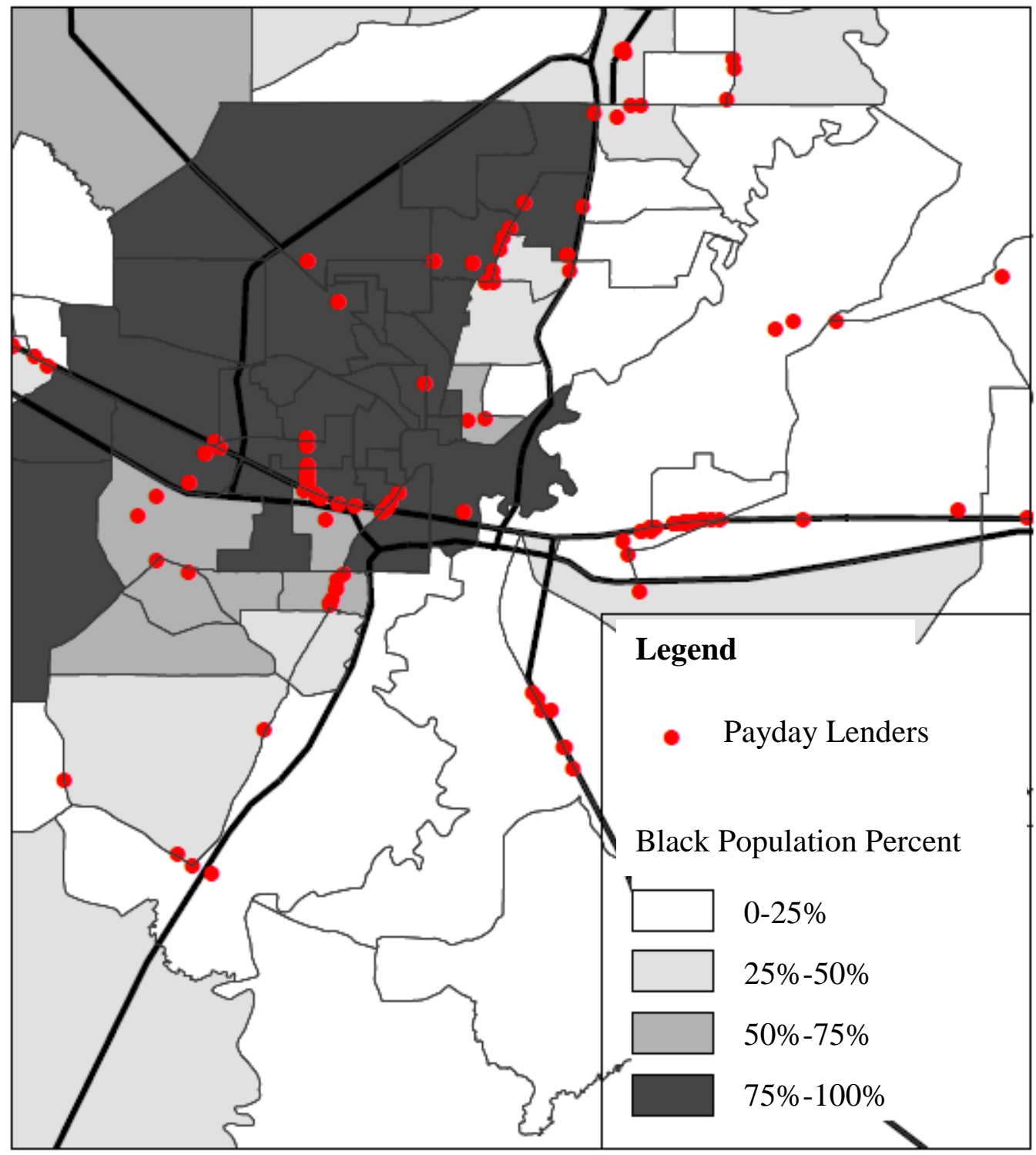

It was expected, as Burkey and Simkins (2004) found using a public assistance variable, that counties with relatively poor populations and higher poverty rates would correlate with lower usages of checking accounts and therefore potentially lower demands for payday lending (Hogarth, Anguelov, and Lee, 2003); however, the statistical analysis does not seem to support this theory uniformly across all levels of aggregation. The research finds that the number of payday lending stores falls with higher proportions of the population in poverty at the ZCTA level but not at the county level. On a speculative basis, one might argue that this issue arises from the nature and extent of markets. In particular, high levels of poverty can reduce the overall demand for payday lending due to lower rates of usage of checking accounts, thus leading to a depressing effect on the numbers of payday lenders in certain small geographic areas. However, it is also the case that many payday lenders now provide an increased range of services beyond payday loans such as money orders, bill paying services, and an array of other services that 
would be well-suited to the poorest families. Consequently, that we find some differences in results across levels of aggregation may arise from differences in the markets for these different services.

The negative coefficient on the regional dummy variable for Katrina affected counties is also robust across levels of data aggregation, pointing to the reduced availability of business locations in the post-hurricane economies in the Gulf Coast region of Mississippi. In the payday lender regressions, the dummy variable for the Mississippi Delta is robust in terms of its negative sign but not in terms of its significance.

The implication of the statistical findings is that there is an optimal market for the payday lending business: ZCTAs/counties with high population and urban designation and lower levels of education on average. But we are unable to find much support for the idea that payday lenders especially target the lowest income communities. When considering policies related to these markets, if it is deemed that high cost loans of the sort provided by payday lenders are not conducive to financial well-being (an issue much debated among such researchers as Stegman and Faris (2003) and Morgan and Strain (2007)), then long-term programs and policies that consider the role of education should be explored further so as to reduce the demand for such services. Secondly, if it is deemed that banks need to make themselves more accessible to African American communities in Mississippi so as to reduce the lower relative access apparent in these results, the proper incentives need to be introduced to increase access to such institutions in minority communities. Finally, given the inability to find evidence supporting claims of minority targeting by payday lenders and the strong evidence in favor of traditional economic factors, any policies intending to change the distribution and location of such stores should focus more on factors related to income, wealth, and, perhaps, given the apparent role of roads in location, on matters of zoning.

\section{REFERENCES}

Bekkerman, Anton, Barry K. Goodwin, and Nicholas E. Piggot (2008) "Spatio-temporal Risk and Severity Analysis of Soybean Rust in the United States," Journal of Agricultural and Resource Economics, 33, 311-331.

Burkey, Mark L. and Scott P. Simkins (2004) "Factors Affecting the Location of Payday Lending and Traditional Banking Services in North Carolina," Review of Regional Studies, 34, 191-205.

Caskey, John P. (1994) Fringe Banking: Check-Cashing Outlets, Pawnshops, and the Poor. Russell Sage Foundation: New York.

Caskey, John P. (2005) "Fringe Banking and the Rise of Payday Lending," Chapter 2 in Patrick Bolton and Howard Rosenthal (eds.), Credit Markets for the Poor. Russell Sage Foundation: New York, pp. 17-45.

Cobb, James C. (1994) The Most Southern Place on Earth: The Mississippi Delta and the Roots of Regional Identity. Oxford University Press: New York.

Cohn, David L. (1935) God Shakes Creation. Harper \& Brothers: New York.

Consumers Federation of America, National Consumer Law Center, and Consumers Union (2008) "Small Dollar Loan Product Scorecard," Available at: http://www.consumerfed.org/pdfs/small_loan_scorecard_08.pdf.

(C) Southern Regional Science Association 2011. 
Damar, H. Evren (2009) "Why Do Payday Lenders Enter Local Markets? Evidence from Oregon," Review of Industrial Organization, 34, 173-191.

Daunfeldt, Sven, Niklas Rudholm, and Fredrik Bergstrom (2006) "Entry into Swedish Retail and Wholesale Trade Markets," Review of Industrial Organization, 29, 213-225.

Elliehausen, Gregory and Edward C. Lawrence, (2008) "A Comparative Analysis of Payday Loan Customers,” Contemporary Economic Policy, 26, 299-316.

Figlio, David N. and Joseph W. Genshlea (1999) "Bank Consolidation and Minority Neighborhoods," Journal of Urban Economics, 45, 474-489.

Flannery Mark and Katherine Samolyk (2005) "Payday Lending: Do the Costs Justify the Price?," FDIC Center for Financial Research Working Paper 2005-09: Washington, DC.

Graves, Steven M. and Christopher L. Peterson (2008) "Usury Law and the Christian Right: Faith Based Political Power and the Geography of the American Payday Loan," Catholic University Law Review, 57, 637-689.

Greene, William H. (1994) "Accounting for Excess Zeros and Sample Selection in Poisson and Negative Binomial Regression Models," Department of Economics, Stern School of Business, New York University Working Paper 94-10.

Greene, William H. (2000) Econometric Analysis. Prentice-Hall, Inc.: Upper Saddle River, NJ.

Hogarth, Jeanne M., Christoslav E. Anguelov, and Jinkook Lee (2003) "Why Households Don't Have Checking Accounts?," Economic Development Quarterly, 17, 75-94.

Lambert, Diane (1992) "Zero-Inflated Poisson Regression with an Application to Defects in Manufacturing," Technometrics, 34, 1-14.

Morgan, Donald P. and Michael R. Strain (2007) "Payday Holiday: How Households Fare after Payday Credit Bans," Federal Reserve Bank of New York Staff Report 309.

Stegman, Michael and Robert Faris (2003) "Payday Lending: A Business Model That Encourages Chronic Borrowing," Economic Development Quarterly, 17, 8-32.

Stegman, Michael A. (2007) "Payday Lending," Journal of Economics Perspectives, 21, 169190.

Willis, John C. (2000) Forgotten Time: The Yazoo-Mississippi Delta after the Civil War. The University of Virginia Press: Charlottesville, VA. 